\title{
EMANCIPAÇÃO E EDUCAÇÃO NO CAPITALISMO EM CRISE: A CONSERVACÇ̃̃O DO APRISIONAMENTO NA APARÊNCIA DA LIBERDADE
}

\author{
Vilson Aparecido da Mata ${ }^{1}$
}

\section{Resumo:}

Este texto pretende discutir a diferença, em Marx, entre emancipação política e emancipação humana e a impossibilidade de uma educação emancipatória no interior da sociedade capitalista. A questão da emancipação é fundamental para a compreensão do discurso educacional da atualidade. A produção de seres humanos como força de trabalho passa inevitavelmente pela educação e por um discurso de emancipação e liberdade que é forjado naturalizando as relações sociais de exploração e expropriação. Neste processo, há o falseamento das verdadeiras condições materiais da crise do capital, ocultando relações sociais que levam o indivíduo não à emancipação humana, mas ao aprisionamento na dependência cada vez mais profunda ao trabalho explorado. Assim como a emancipação política não é um processo natural, mas histórico, a emancipação humana deve ser também uma construção histórica dos homens. Neste sentido, fica claro que os projetos educacionais ditos emancipatórios na atualidade dizem respeito a uma parcialidade, posto que uma educação realmente emancipatória teria de ir à raiz do processo educacional como síntese de múltiplas determinações e essa raiz é o próprio homem, a partir do trabalho, das relações históricas construídas e da perspectiva de superação da ordem social do capital.

Palavras-chave: Emancipação Humana, Trabalho, Educação

\begin{abstract}
:
This text intends to discuss the difference, according to Marx, between the political emancipation and the human emancipation of an emancipatory education within the capitalist society. The emancipation issue is fundamental to the understanding of the current educational discourse. The production of human beings as work force passes inevitably through education and through an emancipation and freedom discourse which is forged, naturalizing the social relations of exploration and expropriation. In this process, there is the distortion of the real material conditions of the capital crisis, hiding social relations that lead the individual not to human emancipation, but to the imprisonment in the dependence deeper and deeper to the exploited labor. As the political emancipation is not a natural process, but a historical one, the human emancipation must be a historical construction of men as well. In this sense, it is clear that the education projects said as emancipatory nowadays concerns a partiality, once a real emancipatory education would have to go to the root of the educational process as a synthesis of multiple determinations and this root is the man itself, from work, historical built relations and the perspective of the capital social order's overcoming.
\end{abstract}

Keywords: Human Emancipation, Work, Education

\footnotetext{
${ }^{1}$ Professor da Universidade Federal do Paraná (UFPR); Doutorando em Educação pela Universidade Federal do Ceará (UFC), vinculado ao Eixo Filosofia, Política e Educação. E-mail: vdamata@hotmail.com.
} 


\section{EMANCIPAÇÃO E EDUCAÇÃO NO CAPITALISMO EM CRISE}

Vilson A. da Mata

\section{Introdução}

Desenvolver reflexões sobre a questão da emancipação e da educação em um contexto de crise do capital significa ter em mente uma dupla determinação: por um lado, a emancipação política das formas societárias anteriores ao capital significou importante avanço para a humanidade; por outro lado, este mesmo movimento, que se colocou como revolucionário em tempos passados significa, hoje, o aprisionamento da liberdade humana nos meandros de uma ordem social permanentemente em crise, desigual intrinsecamente e incapaz de efetivar, para todos os seres humanos, a liberdade prometida em seu nascedouro.

É inegável que o capitalismo trouxe à humanidade importantes avanços. Pela primeira vez, a produção de bens de consumo superou o mínimo necessário à vida de todos os seres humanos; a liberdade civil e a igualdade (ao menos formal, jurídica) entre todos os homens tornou-se desejável; a superação das relações aristocráticas, feudais, nas quais a "cor" do sangue definia quem tinha mais direitos dentro da sociedade.

Porém, o problema com esses avanços é que eles não se efetivaram para todos os seres humanos: se é verdade que nunca se produziu tantos bens de consumo como na atualidade, também é verdade que nunca houve tantos seres humanos alienados dos gozos que esses bens produzidos pelo trabalho proporcionaram.

A emancipação política do jugo da servidão obrigou o trabalhador a entregar-se ao jugo, ainda mais perverso, do trabalho assalariado; garantiu liberdade de vender a força de trabalho, mas aprisionou em relações sociais de exploração ainda mais profundas. $\mathrm{O}$ capitalismo destruiu a propriedade privada baseada em direitos de sangue e privilégios religiosos, emancipando politicamente o ser humano da servidão, mas não foi e nem é capaz de emancipá-lo da propriedade privada individual.

A liberdade do indivíduo entendido como mônada isolada é uma liberdade murada. É como se houvesse uma divisória limitadora da liberdade, para que as ações de uns não prejudiquem as possibilidades de ação de outros. Evidentemente, se é liberdade parcial, então, não é liberdade, porque a sua limitação faz com que o homem dobre-se sobre si mesmo, não vendo a si como ser genérico, ao contrário, faz da vida genérica, da sociedade, algo exterior, estranho, alienado. Fica, assim, evidente a antinomia da emancipação política no contexto do capitalismo em crise: por um lado, liberta os homens do jugo da servidão; por outro lado, não é capaz estender a liberdade a todos os homens. 


\title{
EMANCIPAÇÃO E EDUCAÇÃO NO CAPITALISMO EM CRISE
}

Vilson A. da Mata

Este texto está organizado em três partes. Em primeiro lugar, procura-se evidenciar os limites da emancipação política como necessária em um determinado momento histórico, em que era preciso superar as relações feudais, mas também como uma emancipação ilusória, posto que diz respeito unicamente à parcialidade política. Em segundo lugar, a questão da emancipação humana, conforme a elaboração de Marx, demonstra que a superação do capital demanda uma subjetividade rica, não no sentido material unicamente, mas rica em termos de elevação da cultura, da arte, da educação e da formação do homem. Por fim, a relação entre emancipação e educação a partir da compreensão de que é impossível à educação ser emancipadora no interior da sociedade capitalista a não ser como elemento de ruptura com tal sociedade.

\section{Emancipação Política: a liberdade individual ilusória}

Em Marx, a questão da emancipação política é tratada como sendo uma parcialidade. Embora representando um importante avanço para a humanidade, a constituição do aparato político que dá corpo às liberdades na sociedade capitalista se mostra insuficiente para efetivar a liberdade para todos os seres humanos. A verdadeira questão é a relação entre emancipação política e emancipação humana. O Estado moderno não pode efetivar a emancipação humana porque não é capaz de resolver os males sociais. Isto se dá porque, como criação da sociedade civil burguesa, o Estado moderno tem a função de protegê-la até mesmo em suas contradições.

A separação entre esfera pública e esfera privada é uma expressão tanto do Estado moderno quanto da emancipação política que o funda. O Estado, instância da universalidade, é distanciado da sociedade civil, instância da particularidade:

\begin{abstract}
A constituição do estado político e a dissolução da sociedade civil burguesa nos indivíduos independentes [...] é consumada num só e mesmo ato. O homem como membro da sociedade civil burguesa, o homem não-político, inevitavelmente aparece, não obstante, como homem natural. Os droits de l'homme aparecem como droits naturels, porque a atividade consciente está concentrada na ação política. O homem egoísta é o resultado passivo da sociedade dissolvida, um resultado simplesmente encontrado na existência, um objeto de certeza imediata, portanto, um objeto natural. A revolução política dissolve a vida burguesa em suas partes componentes sem revolucionar essas partes ou submetê-las à crítica. Ela resguarda a sociedade civil burguesa, o mundo das necessidades, o trabalho, os interesses privados, o direito civil. Como a base para sua existência, como a precondição que não requer fundamento e, por isso, como sua base natural ${ }^{2}$.
\end{abstract}

\footnotetext{
${ }^{2}$ MARX, Karl. On the Jewish Question. In: MARX, Karl e ENGELS, Friedrich. Collected Works. New York. International Publishers, 2005; V. 3, p. 167. Grifos do autor.
}

\begin{tabular}{|l|l|l|l|l|}
\hline Revista Dialectus & Ano 1 & n. 1 & Julho-Dezembro 2012 & p. 61-72 \\
\hline
\end{tabular}




\section{EMANCIPAÇÃO E EDUCAÇÃO NO CAPITALISMO EM CRISE}

Vilson A. da Mata

Naturalizadas as relações sociais, a sociedade civil burguesa passa a ser apresentada como sendo a única sociedade possível e o Estado moderno sua expressão máxima. $\mathrm{O}$ homem verdadeiro torna-se o homem burguês, membro da sociedade civil. $\mathrm{O}$ egoísmo é entendido como sua essência atemporal na busca pela satisfação dos interesses particulares no mundo das necessidades, na exploração do trabalho, no lucro, na competição. É a assim chamada natureza humana egoísta que impede a perfeição da eticidade do Estado moderno, não as contradições impetradas pela sociedade civil burguesa. Sendo livre, é responsabilidade do indivíduo a satisfação de suas necessidades. Enquanto, por um lado, o Estado é isento das limitações à liberdade, podendo conduzirse livremente na garantia e conservação das relações sociais burguesas, o indivíduo, tomado como mônada isolada, tem sua liberdade limitada. "Os limites da emancipação política são evidentes imediatamente no fato de que o estado pode ser livre de uma restrição sem que o homem seja realmente livre dela, no fato de que o estado pode ser um estado livre sem que o homem seja homem livre"3.

A emancipação política, então, diz respeito à parcialidade. A cisão entre o homem público (cidadão) e o homem privado (indivíduo) é um traço ineliminável do Estado moderno. A parcialidade política tornou-se universalidade ilusória na efetivação dos direitos humanos como direitos do homem burguês. Um importante elemento da crítica de Marx aos direitos do homem está exatamente no fato de que eles tomam a parcialidade da emancipação política como totalidade ilusória e abstrata da emancipação humana, naturalizando a parcialidade como lei eterna e essência a-histórica do homem. Para Marx: “A liberdade do homem egoísta e o reconhecimento da sua liberdade, porém, é mais propriamente o reconhecimento do irrestrito movimento dos elementos espirituais e materiais os quais formam o conteúdo de sua vida" ${ }^{4}$.

Por ser parcial, limitada, a emancipação política não liberta o ser humano efetivamente, mas, na verdade, o faz cativo, prisioneiro do próprio egoísmo. A própria estrutura que, no início da sociedade moderna pretendia a liberdade do homem tornou- se o calabouço da liberdade, não aboliu seus entraves, mas os aprofundou. A emancipação humana não se realiza na sociedade capitalista.

A conservação da sociedade civil burguesa não efetiva a liberdade porque reduz o humano ao solipsismo: “A necessidade prática, o egoísmo, é o princípio da sociedade

\footnotetext{
${ }^{3}$ Ibid. p. 152. Grifos do autor.

${ }^{4}$ Ibid. p. 167. Grifo do autor.
}

\begin{tabular}{|l|l|l|l|l|} 
Revista Dialectus & Ano 1 & n. 1 & Julho-Dezembro 2012 & p. 61-72 \\
\hline
\end{tabular}




\section{EMANCIPAÇÃO E EDUCAÇÃO NO CAPITALISMO EM CRISE}

Vilson A. da Mata

burguesa, e torna-se visível de forma pura tão logo a sociedade civil extrai completamente

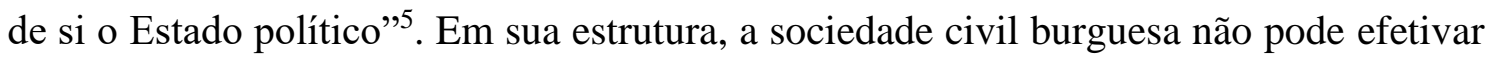
a liberdade humana: a contradição entre capital e trabalho, a competição, o egoísmo, são óbices à liberdade; suas consequências são o aprofundamento da miséria, da exploração, da dissolução da consciência da relação vital, necessária, do homem com o mundo natural e com os demais seres humanos, a redução da subjetividade à mera necessidade prática: "A concepção a que se chega da natureza sob o domínio da propriedade privada e do dinheiro é o real desprezo e a depravação prática da natureza [...]”6.

A emancipação política não é um estágio para a emancipação humana, uma vez que promove a fratura entre o cidadão e o indivíduo privado. A emancipação política é a completude do processo que faz da parcialidade da liberdade política uma universalidade fictícia. "Toda emancipação é a redução do mundo humano, das relações, ao próprio homem. A emancipação política é a redução do homem, de um lado, a membro da sociedade civil burguesa, a uma individualidade egoística, independente, e, de outro, a cidadão, a pessoa moral (juridical)"7. A emancipação política rebaixa até mesmo a cidadania à condição de garantia da esfera privada, do homem parcial.

Fica evidenciada uma universalidade fictícia: o sujeito egoísta surge como a única essência humana possível. A contradição hostil entre a parcialidade e a universalidade faz com que o homem seja entendido como mônada desde os primórdios do capitalismo. A parcialidade põe-se como a própria expressão do sujeito egoísta. A emancipação política reforça a cisão do homem em vida pública e vida privada, pressupondo o aprisionamento deste mesmo homem à ordem da propriedade privada real, desintegrando o homem. Sendo parcial e restrita, não alcança a totalidade das relações histórico-sociais presentes na sociedade, restringindo-se a aspectos isolados, como a educação. Não supera o essencial na alienação e nutre o antagonismo entre a crença na emancipação e a prática social concretamente alienante. Quando se defende a emancipação dentro dos limites da própria ordem que a aprisiona, revela-se unicamente a exortação moral por uma emancipação cindida, parcial, restrita.

\footnotetext{
${ }^{5}$ Ibid. p. 172. Grifos do autor

${ }^{6}$ Ibidem.

${ }^{7}$ Ibid. p. 168. Grifos do aut
}

\begin{tabular}{|l|l|l|l|l|} 
Revista Dialectus & Ano 1 & n. 1 & Julho-Dezembro 2012 & p. 61-72 \\
\hline
\end{tabular}




\title{
EMANCIPAÇÃO E EDUCAÇÃO NO CAPITALISMO EM CRISE
}

Vilson A. da Mata

2. Emancipação Humana: a liberdade efetiva

A necessidade da emancipação só pode existir em um contexto de alienação e estranhamento, tornando-se luta pela sua superação nos limites que se impõem historicamente. O movimento histórico mostra que a mesma estrutura social que aprisiona gesta as condições de sua superação e esta superação é condicionada às possibilidades efetivamente objetivadas socialmente. Somente com a ascensão histórica do capitalismo é que a emancipação humana surge no horizonte como possibilidade efetiva.

Realizar a emancipação humana, porém, não é um processo "natural” da sociedade. Se fosse assim, confirmar-se-ia uma essência a-histórica do homem. Para ser conquistada, a emancipação humana passa pela abolição da propriedade privada dos meios de produção, da exploração da mais valia, da redução do mundo humano ao indivíduo egoísta e burguês. A emancipação humana é projeto consciente de superação dos grilhões do mundo capitalista. Tal projeto não será efetivado sem a luta pelo fim das condições que aprisionam a humanidade na mediocridade. São inegáveis os avanços conquistados em relação à liberdade humana dentro da sociedade capitalista, entretanto:

\begin{abstract}
Somente quando o homem individual real reassimilar em si o cidadão abstrato, como homem individual, como ser genérico, em sua vida diária, em seu trabalho particular e em suas circunstâncias particulares, somente quando o homem tiver reconhecido e organizado suas forces propres, e consequentemente não mais separar o poder social de si mesmo na forma de poder político, somente então a emancipação humana será realizada ${ }^{8}$.
\end{abstract}

A tarefa da emancipação deve ser construída na forma política que implica uma atitude praticamente crítica. A emancipação humana só pode ser conquistada pelos indivíduos organizados em torno do ideal de transformação radical da sociedade. A política precisa ser combatida com a política. Porém, não com a política baseada na vontade, porque esta é uma forma de política que não se constitui como antítese do intelecto político moderno, ao contrário, expressa a parcialidade da emancipação política. O intelecto político obscurece o "instinto social"".

A emancipação humana não se realiza aprisionada à lógica da sociedade da propriedade privada, cujo elemento fundante é a alienação do trabalho que, de antemão,

\footnotetext{
${ }^{8}$ Ibid. p. 168

${ }^{9}$ MARX, Karl. Critical Marginal Notes on the Article "The King of Prussia and Social Reform. By a Prussian". In: MARX, Karl e ENGELS, Friedrich. Collected Works. New York. International Publishers, 2005; V. 3, p. 201.
} 


\section{EMANCIPAÇÃO E EDUCAÇÃO NO CAPITALISMO EM CRISE}

Vilson A. da Mata

a impede. Emancipação humana realiza-se apenas na negação e na superação da ordem social que a aprisiona. É transformação qualitativa, é mudança no modo como as forças produtivas se organizam. Assim sendo, não pode prescindir da ruptura que se dirige à essência do capital: a propriedade privada dos meios de produção e a alienação do trabalho. A emancipação humana não está, portanto, realizada pura e simplesmente no aforismo moral da liberdade nos limites da ordem social vigente. Neste caso, o que há é a expectativa de emancipação política.

O ponto em que se encontra a sociedade hoje obriga os indivíduos a apropriaremse da totalidade das forças produtivas. A transformação da sociedade, a emancipação humana, não é apenas uma necessidade de manifestação livre de si, para o indivíduo contemporâneo, a emancipação humana é, sobretudo, assegurar a existência humana. Mas, a apropriação da totalidade das forças produtivas é condicionada pelas próprias forças produtivas. Isto significa dizer que, na medida em que as forças produtivas do capital se tornaram uma totalidade mundial no interior da qual há o jogo de forças das particularidades nacionais, cabe ao indivíduo revolucionário apropriar-se da totalidade de tais forças, a universalidade deve ser a marca ineliminável da emancipação humana.

\footnotetext{
Por isso mesmo, a apropriação de uma totalidade de instrumentos de produção constitui já o desenvolvimento de uma totalidade de faculdades nos próprios indivíduos. Esta apropriação é ainda condicionada pelos próprios indivíduos que se apropriam. Só os proletários da época atual, totalmente excluídos de qualquer manifestação de si, se encontram em condições de poderem alcançar uma manifestação de si total, não limitada, que consiste na apropriação de uma totalidade de forças produtivas e no desenvolvimento de uma totalidade de faculdades que isso implica ${ }^{10}$.
}

A apropriação da universalidade das forças produtivas só se pode efetivar pela totalidade dos proletários (trabalhadores). O desenvolvimento e a complexificação de uma "totalidade de faculdades" implica o desenvolvimento e a complexificação das capacidades intelectuais dos trabalhadores a fim de apropriarem-se da totalidade das forças produtivas. É certo que o próprio processo revolucionário irá desenvolver as “faculdades dos indivíduos", entretanto, se não houver, a priori, subjetividades ricas, a própria emancipação humana fica comprometida. Não basta que as forças produtivas do capital tenham encontrado seu limite e/ou que a sua crise o lance em derrocada, sem

\footnotetext{
${ }^{10}$ MARX, Karl e ENGELS, Friedrich. The German Ideology. In: MARX, Karl e ENGELS, Friedrich. Collected Works. New York. International Publishers, 2005; V. 5, p. 87.
}

\begin{tabular}{|l|l|l|l|l|}
\hline Revista Dialectus & Ano 1 & n. 1 & Julho-Dezembro 2012 & p. 61-72 \\
\hline
\end{tabular}


uma subjetividade revolucionária rica, a barbárie torna-se assustadoramente mais próxima no horizonte do que a emancipação humana.

\begin{abstract}
É fato, no entanto, que a arma da crítica não pode substituir a crítica das armas, o poder material tem de ser derrubado pelo poder material, no entanto, também uma teoria se transforma em poder material assim que se apodera das massas. A teoria se apodera das massas assim que se evidencia ad hominen [no homem], e de fato ela se evidencia ad hominen tão logo se torna radical. Ser radical significa agarrar a questão pela raiz. Mas a raiz é, para o ser humano, o próprio ser humano ${ }^{11}$.
\end{abstract}

Uma revolução que lance mão apenas da crítica da arma está fadada a se tornar um banho de sangue inútil; uma revolução que permaneça apenas no campo da crítica não é revolução, mas apenas um vago ladrar no deserto. Para que uma transformação social seja viável, a própria realidade material deve demandar a arma da crítica. "A teoria só se efetiva num povo na medida em que representa a caracterização de suas necessidades. [...] Não basta o pensamento insistir na sua caracterização, é preciso que a própria realidade insista no pensamento" ${ }^{12}$.

É na realidade, na vida cotidiana, no dia a dia destruidor, nas idas e vindas do próprio movimento histórico que as condições e a necessidade da transformaçã profunda da sociedade se impõem. Mas não como a necessidade de tornar as condições presentes na sociedade presente mais justas somente, isto seria uma reforma. Na verdade, a necessidade da emancipação humana deve surgir como necessidade profunda de o homem reencontrar-se com sua própria humanidade; como necessidade de alimento, abrigo e calor para toda humanidade, mas também como necessidade estética, de filosofia, de cultura e de poesia; como demanda por aquilo que na sociedade ainda não existe, como desejo coletivo de que o ser humano realize plenamente suas potencialidades. "Uma revolução radical só pode ser a revolução de necessidades radicais, cujas condições prévias e procedências estão justamente ausentes"13.

De que maneira se conhece as condições e procedências ausentes? Pela identificação das falhas, desequilíbrios, limites e contradições presentes. As falhas presentes na sociedade capitalista não são nem podem ser eternas, contudo, sua revolução em uma sociedade que supere as falhas presentes também não pode efetivar- se espontaneamente. A humanidade precisa demandar os potenciais ausentes, precisa

\footnotetext{
${ }^{11}$ MARX, Karl. Contribuição à Crítica da Filosofia do Direito de Hegel - Introdução. São Paulo: Expressão Popular, 2010, p. 44. Ver também: MARX, K. Zur kritik der Hegelschen Rechtsphilosophie - Einleitung. IN: MARX, K. e ENGELS, F. Werke. Berlin: Dietz Verlag, 1981. V. 1. p. 385.

${ }^{12}$ Ibid. p. 46-7. Na edição alemã, p. 386.

${ }^{13}$ Ibid. p. 47. Na edição alemã, p. 387.
}

\begin{tabular}{|l|l|l|l|l|} 
Revista Dialectus & Ano 1 & n. 1 & Julho-Dezembro 2012 & p. 61-72 \\
\hline
\end{tabular}




\section{EMANCIPAÇÃO E EDUCAÇÃO NO CAPITALISMO EM CRISE}

Vilson A. da Mata

agir conscientemente na direção da concretização daquilo que ainda não existe. A revolução radical da sociedade não é um sonho utópico, mas uma possibilidade objetiva de que a humanidade seja capaz de transformar as atuais condições de vida tomando a história em suas mãos. Sonho utópico, na verdade, é a crença de que as instituições secularmente responsáveis pela miséria humana sejam capazes de "melhorar" a sociedade capitalista através da política democrático burguesa. A revolução radical é a expressão de uma realidade que demanda o pensamento crítico na ação crítica e a ação crítica de pensar de forma emancipadora.

Somente quando o homem perder-se de si, exteriorizar-se no mundo e reconhecer a si próprio no mundo, sem mais estranhamento, é que poderá recuperar-se completamente como ser humano. Perder-se de si significa exteriorizar-se, apropriar-se da totalidade das relações concretizadas historicamente; significa pôr-se para fora de sua atual condição de sofrimento e brutalização. O reconhecimento da própria condição desumana criada pelo capital é um dos fatores indispensáveis para que, a partir de então, o humano se reconheça como humano apenas no seu ser genérico, e não mais naquilo que desumaniza.

Para transformar a sociedade é necessário, dentre outros elementos, diminuir a fronteira do conhecimento entre as classes. A classe trabalhadora é oprimida pela classe possuidora dos meios de produção não só materialmente, mas também e fundamentalmente submissa e inerte culturalmente. Sem o conhecimento teórico não há domínio teórico e, sem domínio teórico, não há possibilidade de a classe trabalhadora superar o domínio ideológico da classe dominante. Se é absurdo pensar na transformação do mundo tendo como base a vontade individual ou a transformação do indivíduo, não é, contudo, absurdo considerar que a transformação do mundo deve ter determinação recíproca com a transformação do indivíduo. A transformação que mantém no horizonte da humanidade a perspectiva de um mundo mais humano para todos contém já a afirmação de uma subjetividade também transformada e transformadora que, na medida em que efetiva a liberdade humana, traz consigo a efetivação da liberdade individual que constrói uma sociedade sem desigualdades, uma sociedade do trabalho não alienado, concretizando uma subjetividade rica, independente, com capacidade de desenvolver infinitamente suas potencialidades. 


\section{Emancipação e Educação: limites da concepção redentora da educação}

Um ideal de transformação radical da sociedade deve passar, inevitavelmente, pela educação. A transformação social radical é impossível sem uma formação humana radical. Por isso, conceber a educação como instância capaz de transformar os horizontes individuais desconsiderando-se a totalidade histórica que engendra os processos educacionais é entendê-la como tendo um papel redentor, quase místico, de transformar pela ação isolada a sociedade toda.

O cerne das propostas educacionais que se consideram emancipadoras está na defesa da tese de que, pela educação, as situações de pauperismo e subdesenvolvimento podem ser superadas; pela educação, o indivíduo pode vir a ser o empreendedor do próprio sucesso, entendido este como sendo o sucesso burguês da acumulação egoísta de capital. A formação técnica e a capacidade de trabalho do homem seriam o caminho pelo qual a educação contribuiria para a liberdade humana.

À educação caberia o papel de formar as mentes e braços capazes de elevar a sociedade a um patamar de desenvolvimento condizente com os ideais de igualdade e de gozo das benesses do mundo do consumo globalizado. O foco no processo de aprender, e não no produto da aprendizagem, efetiva uma educação desocupada de pensar o futuro, desvinculada de uma teleologia e que pretende assegurar ao aprendiz a possibilidade de se tornar sujeito de sua própria história e, por si só, este processo enriqueceria as possibilidades renovadas de uma sociedade em transformação. O dístico do progresso e da transformação social está presente como sendo o produto da iniciativa individual, do aprendiz sujeito de sua própria aprendizagem, capaz de, a partir de suas impressões pessoais, transformar toda uma realidade histórica. A emancipação, assim, seria proveniente de uma vontade, independeria da história real. Esta vontade fundamentaria uma ação em direção à emancipação dos homens.

É importante ressaltar que, sem a educação, não será possível a emancipação humana, e esta é uma positividade das concepções ditas “emancipatórias". Entretanto, quando a educação é entendida como a instância propulsora das transformações que levarão à extirpação da sociedade daquilo que é "mal" (a pobreza, a miséria, a violência, etc.), ao mesmo tempo em que cultiva e promove aquilo que é "bom" (generosidade, amor, paz, etc.), não se mostra capaz de realizar a emancipação humana universalmente. A educação termina por assumir o discurso moral da reforma parcial, reforçando o sujeito egoísta a partir do contraditório discurso do bem de todos.

\begin{tabular}{|l|l|l|l|l|} 
Revista Dialectus & Ano 1 & n. 1 & Julho-Dezembro 2012 & p. 61-72 \\
\hline
\end{tabular}




\section{EMANCIPAÇÃO E EDUCAÇÃO NO CAPITALISMO EM CRISE}

Vilson A. da Mata

Atribuir à vontade política (parcial, individual) a realização de qualquer programa emancipatório não atinge o sustentáculo daquilo que aprisiona a liberdade humana: a sociedade da propriedade privada dos meios de produção. O Estado burguês não tem condições de eliminar as desigualdades sociais, nem pela educação, nem por qualquer outro meio. Conforme Marx: "Para educar as crianças, é preciso alimentá-las e liberá-las da necessidade de trabalhar para viver. Alimentar e educar as crianças abandonadas, isto é, alimentar e educar todo o proletariado que está crescendo, significaria eliminar o proletariado e o pauperismo"14. Eliminar o proletariado e o pauperismo significaria eliminar o próprio capitalismo.

A emancipação humana só pode começar com a anulação, a destruição e a superação da propriedade privada dos meios de produção. Isto as "propostas emancipatórias" desconsideram por completo. Não supõem a superação da luta de classes ou da propriedade privada burguesa, ao contrário, as reforça, aprofundando a universalização do isolamento brutal do homem em relação a sua comunidade, em relação a sua própria vida. Se a essência humana é a verdadeira comunidade humana, então a essência humana isolada da totalidade das relações sociais e históricas encaminha o isolamento universal do homem, efetivado em concepções educacionais parciais, que não suprimem tal isolamento, mas dão-lhe corpo. Priva-se o homem do entendimento de que produz socialmente a si mesmo.

Clamar pela educação emancipatória, sem superar as forças produtivas que nutrem a alienação é proferir discurso de reformismo moral. A desejada emancipação pela educação não se realiza porque pretende emancipar a partir da mesma estrutura que aprisiona. Ao perceber a alienação do homem do ponto de vista do capital, a educação não tem condições de propor sua superação a não ser no quadro dos postulados morais mais gerais e na conformação reformista, "melhorando", "humanizando", por assim dizer, o capitalismo.

A superação da alienação e a conquista da emancipação é também uma tarefa educacional, porém, apenas quando esta tarefa assume o caráter de ruptura profunda. A transcendência das relações sociais alienadas só pode ser concebida no quadro geral das relações sociais construídas. A contradição hostil entre particularidade e universalidade reflete-se na educação: quando tomada isoladamente, alienada de sua determinação histórica e social, assume a forma de uma atividade alienante, que produz homens e

\footnotetext{
${ }^{14}$ MARX, Karl. Critical Marginal Notes on the Article "The King of Prussia and Social Reform. By a Prussian”. In: MARX, Karl e ENGELS, Friedrich. Collected Works. New York. International Publishers, 2005; V. 3, p. 192.
}

\begin{tabular}{|l|l|l|l|l|}
\hline Revista Dialectus & Ano 1 & n. 1 & Julho-Dezembro 2012 & p. 61-72 \\
\hline
\end{tabular}




\section{EMANCIPAÇÃO E EDUCAÇÃO NO CAPITALISMO EM CRISE}

Vilson A. da Mata

mulheres para o mercado de trabalho reificado. A educação, tomada a partir do ponto de vista da universalidade, é atividade social que produz o ser humano capaz de inventar potencialidades e usufruir dessas mesmas potencialidades socialmente.

A ênfase de $\operatorname{Marx}^{15}$ é de que a teoria só se efetiva num povo na medida em que representa a concretização de suas necessidades. Mais que isso, a teoria é o corolário da emancipação humana, entendida como a emancipação que não deixa os pilares da casa em pé, que destrói a velha sociedade e institui a nova, que supera a estrutura social antiga, preservando suas conquistas. A teoria só pode tornar-se material quando a sociedade em geral se confunde com ela, reconhecendo-a como sua representante universal. O papel da educação, numa perspectiva emancipatória, é o de orientar a promoção da superação da parcialidade das relações políticas e da emancipação política. Porém, um projeto como este é impossível se pensado apenas a partir do ponto de vista da educação, posto que ela é uma instância da sociedade democrático burguesa que, embora expressando a totalidade dos processos sociais, necessita de todas as demais instâncias para efetivar seu papel emancipatório.

\section{Referências Bibliográficas}

MARX, K. Zur kritik der Hegelschen Rechtsphilosophie - Einleitung. IN: MARX, K. e ENGELS, F. Werke. Berlin: Dietz Verlag, 1981. V. 1. p. 378-391.

MARX, Karl. On de Jewish Question. IN: MARX, Karl e ENGELS, Friedrich.

Collected Works. New York: International Publishers, 2005 (Volume 3); p. 146 - 174.

MARX, Karl. Critical Marginal Notes on the Article The King of Prussia and Social Reform. By a Prussian. In: MARX, Karl e ENGELS, Friedrich. Collected Works. New York. International Publishers, 2005; V. 3, p. 189-206.

MARX, Karl e ENGELS, Friedrich. The German Ideology. In: MARX, Karl e ENGELS, Friedrich. Collected Works. New York. International Publishers, 2005; V. 5, p. 19-451.

MARX, Karl. Contribuição à Crítica da Filosofia do Direito de Hegel - Introdução. São Paulo: Expressão Popular, 2010.

\footnotetext{
${ }^{15}$ MARX, Karl. Contribuição à Crítica da Filosofia do Direito de Hegel - Introdução. São Paulo: Expressão Popular, 2010. Ver também: MARX, K. Zur kritik der Hegelschen Rechtsphilosophie - Einleitung. IN: MARX, K. e ENGELS, F. Werke. Berlin: Dietz Verlag, 1981. V. 1.
} 